\title{
Calcinose Universal no Lúpus Eritematoso Sistêmico
}

\section{Calcinosis Universalis in Systemic Lupus Erythematosus}

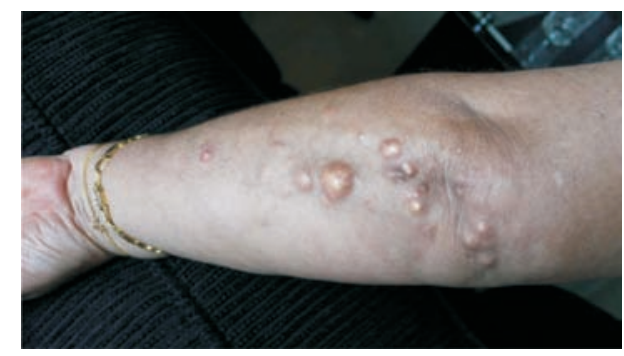

Figura 1 - Calcinose no cotovelo esquerdo.

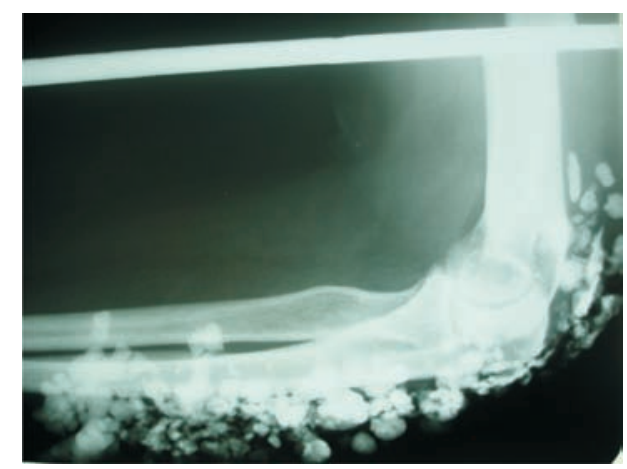

Figura 3 - Radiografia mostrando calcinose no cotovelo.

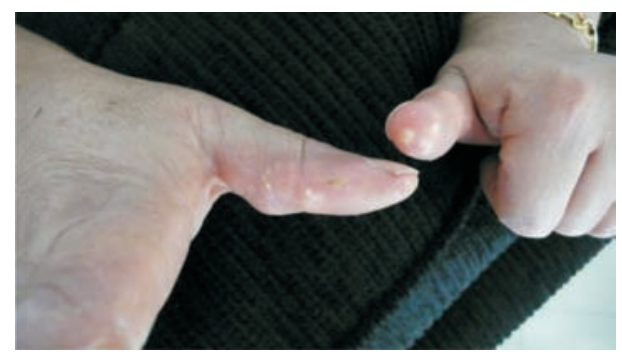

Figura 2 - Calcinose nos quirodáctilos.

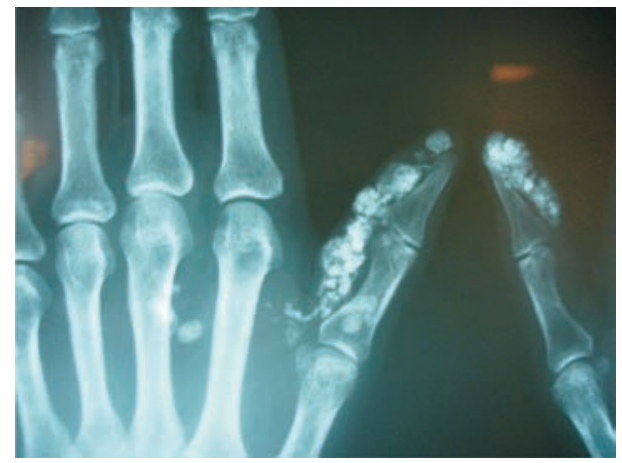

Figura 4 - Radiografia mostrando calcinose nos quirodáctilos.

Paciente do sexo feminino, 59 anos, com lúpus eritematoso sistêmico (fotossensibilidade, rash malar, poliartrite, linfopenia, FAN e anti-Ro/SS-A positivos) desde 1995. Atualmente, em uso somente de hidroxicloroquina, $400 \mathrm{mg}$ em dias alternados, por não apresentar nenhum sinal clínico e/ou laboratorial de atividade da doença há quatro anos. Apresentava, desde 2002, presença de calcinose de cotovelos (Figura 1), ombros e dedos (Figura 2), confirmadas pelas radiografias dos citados locais (Figuras 3 e 4). As dosagens de cálcios sérico e urinário, fósforo, fosfatase alcalina, creatinina, 25-OHvitamina D e paratormônio foram normais. Não apresenta alterações clínicas compatíveis com esclerodermia, miosite ou síndrome de Sjögren. Capilaroscopia, tomografia de alta resolução do tórax, espirometria, ecocardiograma, esofagograma, enzimas musculares, testes de Schirmer e rosa bengala, cintilografia de glândulas salivares normais. Anti-Scl-70, ENA e Jo-1 negativos. Fez uso de hidróxido de alumínio $(80 \mathrm{~mL} / \mathrm{d})$, warfarin $(1 \mathrm{mg} / \mathrm{d})$, alendronato $(70 \mathrm{mg} / \mathrm{sem})$, diltiazem (360 mg/dia) e colchicina sem melhora da calcinose. Atualmente, em uso de pamidronato bimensal com melhora discreta do quadro clínico; além de fisioterapia e hidroterapia para melhora da amplitude de movimentos e qualidade de vida. O presente caso se trata de uma paciente com lúpus eritematoso sistêmico estável, sem atividade clínico-laboratorial há anos, entretanto com calcinose universal em progressão.

Caso encaminhado pelo médico Jozélio Freire de Carvalho, médico-assistente, doutor do Serviço de Reumatologia do Hospital das Clínicas da Faculdade de Medicina da Universidade de São Paulo (HCFMUSP). Disciplina de Reumatologia da FMUSP, Av. Dr. Arnaldo, 455, sala 3.190, Cerqueira Cesar, 012467-903, São Paulo, SP, e-mail: jotafc@gmail.com 